\title{
A Função das Dúvidas Céticas nas Meditações de Descartes
}

\author{
Flavio Williges \\ Curso de Filosofia da Universidade de Santa Cruz do Sul- UNISC \\ williges@unisc.br ou fwilliges@gmail.com
}

\begin{abstract}
resumo 0 objetivo central deste artigo é sustentar que as hipóteses céticas presentes na Primeira Meditação, especialmente a dúvida acerca das coisas materiais, devem ser entendidas como uma espécie de exercício mental proposto como expedie nte para fragilizar a confiança nos sentidos e preparar o leitor das Meditações para a apreensão de verdades acessíveis à luz da razão. Nesse sentido, pretende-se most rar que a dúvida cética desempenha, na economia das Meditações, uma função muito mais positiva, construtiva, do que propriamente negativa, de ins tau ração do ceticismo filosófico acerca do mu ndo exterior, tal como ela tem sido freqüentemente representada nos debates epistemológicos contemporâneos. A estratégia que permitiu tal leitura consistiu em valorizar o aparecimento das dúvidas céticas no interior de um texto escrito em estilo meditativo e em destacar certos elementos das circunstâncias intelectuais que envolveram a revolução científica vivenciada por Descartes.
\end{abstract}

palavras-chave Descartes; dúvidas céticas; ciência; ceticismo; epistemologia

\section{1- As dúvidas céticas e a epistemologia contemporânea}

O ceticismo filosófico quanto ao conhecimento do mundo exterior pode ser caracterizado através da tese de que ninguém sabe nada sobre o mundo físico ao seu redor, nem mesmo que ele existe (STROUD, 1984, p.1). Em liv ros e artigos de epistemologia contemporânea, a análise dessa forma de ceticismo parte, em geral, das Meditações Metafísicas, tendo em vista o uso que Descartes fez, na Primeira Meditação, de dúvidas céticas². 


\section{4}

Mas há razões para suspeitar que as motivações filosóficas de Descartes ao formular dúvidas céticas não eram, ao menos não inteiramente, as mesmas que animam o debate epistemológico atual entre "céticos" e "anticéticos", onde os últimos estariam interessados em provar ve rdades básicas, como a existência do mundo exterior, diante de dúvidas hiperbólicas, do tipo das levantadas nas Meditações. A atenção ao contexto intelectual que forneceu o solo para o surgimento das Meditações torna possível reconhecer, dentre outras coisas, que Descartes procural estabelecer ceticamente, no final da Primeira Meditação, "que o céu, o ar, a terra... e todas as coisas exteriores que vemos são apenas ilusões e enganos...” (DESCARTES, 1979, p. 12) por ter em vista conseqüências diferentes daquelas que chamam a atenção dos epistemólogos contemporâneos e que poderiam ser derivadas da apresentação desse mesmo argumento.

Uma clara indicação da diferença de perspectiva quanto àquilo que chamou atenção de Descartes nos argumentos céticos em relação à abordagem da epistemologia contemporânea aparece quando ele afirma, acerca das razões ofertadas para refutar a dúvida acerca da existência das coisas materiais, que tais razões não foram pensadas como

muito úteis para provar o que elas provam, a saber, que há um mundo, que os homens têm corpos e outras coisas semelhantes, que nunca foram postas em dúvida por homem algum de bom senso; mas porque, considerando-as de perto, chega-se a conhecer que elas não são tão firmes nem tão evidentes quanto aquelas que nos conduzem ao conhecimento de Deus e da nossa alma; de sorte que estas últimas são as mais certas e as mais evidentes que possam cair no conhecimento do espírito humano (DESCARTES, 1979a, p.80-81).

Descartes afirma que os argumentos que apresentou para provar coisas que nunca foram postas em dúvida por homens de bom senso ("que há um mundo, que os homens têm corpos e outras coisas semelhantes") refutam realmente as dúvidas que o obrigaram a interpor uma prova, mas, ainda, ele não deixa de ressaltar que esses argumentos tinham uma outra utilidade: reconhecer que há conhecimentos bem mais firmes e certos do que este, como é o caso do conhecimento de Deus e da alma. O itinerário de embate com o ceticismo, que começa com a dúvida e termina 
na prova de que há coisas materiais, não é retratado aqui como tendo a centralidade que veio a assumir nas análises epistemológicas contemporâneas.Toda a preocupação com a dúvida e sua refutação aparece como projetada para destacar a firmeza e evidência de verdades metafisicas que pareciam mais obscuras e dificeis de conhecer pelo espírito humano do que o mundo fisico.

Uma leitura informada pelas circunstâncias intelectuais envolvidas no projeto de elaboração da Primeira Meditação e do emprego da dúvida revela um resultado semelhante. A função da dúvida cética não aparece tão atrelada à articulação do ceticismo sobre o mundo exterior discutido na atualidade. As dúvidas parecem assumir uma função muito mais positiva, de modo que um primeiro requisito que qualquer estudo apropriado do envolvimento de Descartes com o ceticismo deve ser capaz de cumprir é mostrar o que seria essa função das dúvidas céticas, uma função que aponta para além do ceticismo filosófico contido na própria dúvida.

Como o próprio Descartes se encarregou de deixar claro em algumas passagens, o meditador não terá dificuldades em reconhecer que a dúvida tinha objetivos construtivos, era, por assim dizer, dogmática e não cética. As anotações que apresentari a seguir têm a pretensão de explicitar esse aspecto positivo da dúvida na economia das Meditações. O principal argumento que desenvolverei será que a dúvida tinha a pretensão fragilizar nossa confiança nos sentidos e preparar o leitor para a apreensão de verdades acessíveis à luz da razão. A dúvida acerca das coisas materiais não tinha tanto a pretensão de estabelecer uma conclusão filosófica (cética e provisória), mas muito mais propor um "exe rácio meditativo" que nos conduziria à sugestão de que a realidade exterior pode ser uma ilusão e que, portanto, não caberia confiar nos sentidos como guia para o conhecimento. O leitor assim convencido estaria preparado para reconhecer a função da razão no conhecimento. Para fazer isso, minha estratégia de leitura consistirá em traçar um quadro das circunstâncias intelectuais que envolveram a revolução científica vivenciada por Descartes e em conceber as meditações como uma série dinâmica de exercícios e não um conjunto estático de "fatos" (COTTINGHAM, 1995, p.110). 


\section{2- A dupla função da dúvida nas Meditações}

Descartes menciona a função que ele pensou que deveria ser desempenhada pelas dúvidas céticas em várias passagens de seus escritos. Nas Segundas Respostas, ele explica que seguiu a via analítica e não o método sintético dos geômetras ao escrever as Meditações, pois a mesma facilitaria o ensino das primeiras verdades da Metafísica.

Quanto a mim, segui somente a via analítica em minhas Meditações, por que me parece ser a mais verdadeira e a mais própria ao ensino $[\ldots]$ a síntese não convém, todavia, tão bem às matérias que pertencem à Metafisica. Pois há essa diferença que as primeiras noções supostas para demonstrar as proposições geométricas, estando de acordo com os sentidos, são facilmente aceitas por cada qual [...]Mas, ao contrário, no atinente às questões que pertencem à Metafisica, a principal dificuldade é conceber clara e distintamente as noções primeiras. Pois, ainda que por sua natureza não sejam menos claras, sendo mesmo muitas vezes mais claras do que as consideradas pelos geômetras, não obstante, posto que parecem não concordar com muitos prejuízos que recebemos através dos sentidos, e aos quais nos habituamos desde a infầncia, são perfeitamente compreendidas apenas pelos que são muito atentos e se empenham em apartar, tanto quanto podem, o espírito do comércio dos sentidos; eis por que, se as propuséssemos totalmente a sós, seriam facilmente negadas por aqueles cujo espírito é propenso à contradição (DESCARTES, 1979c, p. 167).

O gesto de Descartes aqui é indicar que, para que o leitor pudesse aceitar e compreender as primeiras verdades da Metafísica seria necessário adotar um procedimento adequado de exposição de sua doutrina. Esse procedimento é o método analítico de exposição. A adoção do método de análise foi feita em função do tipo de leitor que Descartes pretendia atingir. Para um leitor "acostumado com os prejuízos que recebemos através dos sentidos", a apresentação direta das noções primeiras partindo de definições, postulados, axiomas e teoremas, como faziam os geômetras, poderia simplesmente gerar resistência ou a negação das ve rdades que seriam propostas. Para evitar esse resultado danoso, Descartes considerou que a melhor estratégia seria conduzir o meditador ao descobrimento das 
teses fundamentais da Metafísica de uma maneira que ele mesmo não poderia recusar. A análise "mostra o verdadeiro caminho pelo qual uma coisa foi metodicamente descoberta e revela como os efeitos dependem das causas; de sorte que, se o leitor quiser segui-la e lançar cuidadosamente os olhos sobre tudo o que contém, não entenderá menos perfeitamente a coisa assim demonstrada e não a tornará menos sua do que se ele próprio a houvesse descoberto" (DESCARTES,1979c, p.166). O método de análise "prepara" a descoberta das verdades através de mecanismos como a exposição gradual, a introdução de informações que permitirão realizar inferências que conduzirão ao descobrimento de novas verdades e a recursividade ou retomada dos resultados obtidos antes de ingressar em cada novo estágio do percurso investigativo.

Como as ve rdades metafísicas não concordam com os preconceitos herdados dos sentidos, uma parte essencial dessa preparação das verdades para o leitor consiste justamente em "apartar seu espírito do comércio dos sentidos". O método analítico incorpora, assim, expedientes pensados com a função especial de remover os obstáculos que poderiam atrapalhar o caminho reflexivo seguido pelo investigador em direção às primeiras verdades. Essa tarefa, diz claramente Descartes, será realizada mediante o emprego de dúvidas céticas.

$\mathrm{Na}$ primeira, adianto as razões pelas quais podemos duvidar geralmente de todas as coisas, e particularmente das coisas materiais, pelo menos enquanto não tivermos outros fundamentos nas ciências além dos que tivemos até o presente. Ora, se bem que a utilidade de uma dúvida tão geral não se revele desde o início, ela é todavia nisso muito grande, porque nos liberta de toda sorte de prejuízos e nos prepara um caminho muito fácil para acostumar nosso espírito a desligar-se dos sentidos...(DESCARTES, 1979a, p. 79)

Como fica claro aqui, as dúvidas céticas, particularmente a dúvida sobre as coisas materiais, representam um expediente para "acostumar nosso espírito a desligar-se dos sentidos”, sendo tal operação necessária, junto com o método analítico, para que o leitor das Meditações seja capaz de apreender as primeiras verdades da Metafisica cartesiana.

Descartes atribuiu essa mesma função às dúvidas nas respostas a Hobbes, quando afirma que as razões para duvidar foram pensadas "para 
preparar o espírito dos leitores a considerar as coisas intelectuais e distingui-las das coisas corpóreas" e acrescenta que elas serão respondidas nas meditações seguintes, dando lugar às "primeiras verdades", as quais servirão "para mostrar quão firmes são as verdades avançadas", visto que elas "não serão abaladas por dúvidas tão gerais e extraordinárias"(DESCARTES,1999, p. 600). A dúvida, reitera aqui Descartes, servirá para preparar o leitor para a consideração das coisas intelectuais (verdades metafisicas), sendo que as verdades obtidas não terão sua certeza afetada pela dúvida assumida no percurso da investigação. Essa mesma posição é estabelecida no diálogo A Busca da Verdade, onde Descartes faz Eudoxo, um dos interlocutores, dizer que “...pois dessa dúvida universal, como de um ponto fixo e imóvel, eu fa rei derivar o conhecimento de Deus, aquele de nós mesmos e, enfim, aquele de toda as coisas que existem na natureza" (DESCARTES, 1999, p. 1122).

O emprego da dúvida é, assim, um caminho que não só não pretende frustrar nossas pretensões epistêmicas, como promete a obtenção de conhecimento absolutamente certo ou indubitável. Em suma, a dúvida se prestará, ao mesmo tempo, para duas funções distintas e interligadas: a remoção dos obstáculos (prejuízos dos sentidos) e a apreensão de verdades indubitáveis.

Para entender melhor como essas duas funções poderiam ser desempenhadas pelas dúvidas céticas é essencial compreender sua aparição no interior de uma doutrina apresentada ao leitor num estilo meditativo.

\section{3- Meditações filosóficas}

No Ocidente, as meditações constituem um estilo de escrita filosófica com uma história que remonta à Antiguidade Clássica, tendo se originado, possivelmente, entreos filósofos da Escola Estóica. As meditações clássicas consistiam em anotações de cunho pessoal, cuja função era fixar a prática do modo de vida preconizado pela escola. Um caso paradigmático de tal modelo são as meditações de Marco Aurélio, que se constituíam num aglomerado de notas pessoais sobre temas de reflexão, escritas para relembrar ou instituir um ou outro estado de espírito conveniente aos preceitos racionais do estoicismo (HADOT, 1996, p. 320). Na tradição cristã, as meditações ainda conservam o estatuto de um exercício íntimo, 
mas não são mais notas ou temas de reflexão estritamente pessoal; elas dirigem-se a um público mais amplo, interessado em sua salvação.

Meditações de caráter religioso foram comuns na época de Descartes. Ignácio de Loyola, fundador da Ordem dos Jesuítas, escreveu um livro meditativo chamado Exercícios Espirituais, onde define um exercício espiritual como um modo de examinar a consciência por meditação, contemplação ou oração em silêncio ou voz alta e afirma que "as necessidades da alma normalmente não encontram satisfação em uma série de fatos, mas sim em um sentido e desejo interno pelas coisas"(COTTINGHAM, 1995, p.110).

A composição das meditações de Descartes foi influenciada por este modelo da meditação como exe rćicio espiritual. E é justamente esse sentido de meditação e atenção que Descartes exige de seus leitores. Nas Segundas Respostas, ele afirma:"preferi escrever meditações e não disputas ou questões, como fazem os filósofos, ou teoremas e problemas, como os geômetras, a fim de testemunhar que as escrevi tão-somente para os que quiserem dar-se ao trabalho de meditar seriamente comigo e considerar as coisas com atenção" (DESCARTES, 1979c, p. 167). "Meditar seriamente comigo" significa acompanhar o percurso do autor das Meditações Metafísicas através de cada um de seus estágios. A estrutura de um texto meditativo impõe, nesse sentido, uma relação peculiar entre leitor e autor, onde a intelecção do texto e dos propósitos do autor depende do acompanhamento devotado de todo o percurso por ele realizado. Não é por acaso que elas foram projetadas como reflexões de um pensador isolado do mundo e escritas por alguém que, ao examinar suas próprias crenças, pretendia servir de modelo ou exemplo para outros. Segundo Hatfield,

“as meditações religiosas são em geral descrições de pessoas buscando salvação, pessoas que começam na escuridão do pecado e são conduzidas à conversão por iluminação espiritual. Embora o propósito de tais escritos sejam instruir e iniciar os outros, o método não é essencialmente didático. $\mathrm{O}$ autor empenha-se em ensinar mais pelo seu exemplo do que por preceitos. Em um amplo sentido, as Meditações são um trabalho deste tipo: o objetivo de Descartes é guiar o leitor à salvação intelectual por contar a sua própria descoberta da razão e a fuga da confiança cega nos sentidos, os quais tinham formalmente aprisionado-o na ilusão e no erro"(HATFIELD, 1986, p.50). 
$\mathrm{Na}$ Meditação, o autor é reconhecido como um guia, um exemplo a ser seguido. O leitor descobre o autor, seguindo-o. Trata-se, assim, de um itinerário pessoal que possui um apelo irrestrito ou universal. O "eu" cart esiano, apesar de ser solitário, é uma condição que cada um de nós pode experimentar, desde que acompanhe os passos dados pelo autor.

Por outro lado, enquanto as meditações religiosas pretendiam despertar a piedade dos leitores voltando-os para a única fonte da verdade e salvação na aceitação da verdade divina (cristã) com base na fé, o estilo meditativo de Descartes combina elementos demonstrativos, ou seja, ele pretende revelar a capacidade do meditador de evitar o erro e descobrir a verdade sem o apoio em qualquer autoridade senão aquela da razão. $\mathrm{O}$ leitor deve reconhecer, segundo uma ordem de descoberta dinâmica e fazendo uso da razão natural, o encadeamento e as relações entre as diferentes ve rdades que são apresentadas. Essas verdades, no entanto, não poderiam se tornar algo herdado pelo leitor sem a ajuda da experiência. Como afirma Michelle Beyssade,

as razões por vezes se ligam e se cruzam na demonstração, razões e exercícios relacionam-se e se entrelaçam na meditação. Assim, eles se fecundam mutuamente. As razões, experimentadas, não permanecem externas ao sujeito que medita e a experiência, mais do que em outros casos, eleva-se à universalidade da razão. $\mathrm{O}$ gênero meditativo associa a demonstração e a experiência, a ciência e o exercício, o sistema e a ascese (BEYSSADE, 1996, p.111).

Cada meditação representa, nesse sentido, um estágio necessário para alcançar o propósito mais geral de uma doutrina que pretende ser, a um só tempo, demonstrada e experimentada. A peregrinação através das meditações religiosas tinha em vista uma conversão ou transformação através do despertar da fé. Descartes não pretendeu provocar uma transformação interior, mas gerar uma transformação teórica no leitor, que essencialmente consistia em fazê-lo abandonar sua confiança cega nos sentidos e assumir uma nova epistemologia centrada nos poderes da razão.

Uma meditação cartesiana é, assim, uma experiência reflexiva que atua sobre o próprio meditador, ajudando-o a superar certas dificuldades na direção do reconhecimento de uma nova ordem filosófica, de modo que 
ler o texto meditativo cartesiano, especialmente a Primeira Meditação, que confronta o leitor através da apresentação de um conjunto de dúvidas, deve ser visto como uma ação que participa de uma estratégia mais ampla, a qual encontra-se centrada na pretensão de revelar certas verdades acessíveis à luz da razão que, de outro modo, não seriam apreendidas pelo leitor. É justamente por isso que Descartes considerou importante dedicar uma meditação inteira a tarefa de "duvidar de tudo e principal mente das coisas corpóreas" e afirma que "gostaria que os leitores empregassem não apenas o pouco tempo necessário para lê-la, mas alguns meses, ou ao menos algumas semanas, antes de passar além". (DESCARTES, 1979c, p. 152, 167). As razões de duvidar p resentes na Primeira Meditação surgem, quando vistas a partir da opção pelo estilo de redação das Meditações não tanto como argumentos céticos, mas mais como exercícios espirituais, meditativos, destinados a apartar o leitor da confiança nos sentidos, capacitando-o para o reconhecimento de verdades metafísicas absolutamente certas que servirão de base para o projeto de fundamentação da ciência cartesiana ${ }^{3}$.

Mas, qual o projeto de transformação teórica de Descartes ao escrever as Meditações Metafísicas? Se os exercícios meditativos não visavam à dúvida quais verdades o conjunto das seis meditações cartesianas pretendia estabelecer? Por que ele considerou que a epistemologia sensualista deveria ser rejeitada mediante dúvidas céticas e substituída por uma nova epistemologia fundada na razão?

\section{4- A matéria como extensão, a ciência moderna e a epistemologia cartesiana.}

Descartes descreveu o seu projeto filosófico nas Meditações como uma tentativa de estabelecer os fundamentos de uma Física emancipada dos princípios que governavam a ciência da natureza de A ristóteles. Numa célebre carta enviada a Mersenne, ele comenta que as "seis meditações contêm todas as fundações de minha Física" e observa que tais fundações “abalam aquelas de Aristóteles" (DESCARTES apud WILSON, 1978, p.2). Margareth Wilson acrescenta, como comentário a esta carta, que a Física cartesiana "foi, de fato, altamente instrumental em 'destruir os 
princípios de Aristóteles' - ao estabelecer o conceito de uma ciência universal da matéria que procurava explicar todos os fenômenos em termos de propriedades básicas quantificáveis e leis simples governando o movimento" (WILSON, 1978, p.3). A referência às propriedades quantificáveis dos fenômenos pode ser perfeitamente compreendida se observarmos que a ciência da natureza de Descartes tinha como uma de suas bases metafisicas fundamentais a idéia de que a essência das coisas corpóreas é a extensão, a qual é "o objeto da Geometria especulativa" (DESCARTES, 1979a, p.96-97, 135). De fato, Descartes escreveu a Mersenne, "toda minha física não é outra coisa que geometria" (DESCARTES apud HATFIELD, 1998, p. 281n) e tal afirmação deve ser entendida como significando que ele irá considerar como essencial para a Física apenas aquilo que puder ser descrito geometricamente, isto é, a matéria (substância extensa) em movimento (este descrito cinematicamente). “Admito sem restrições que não há nas coisas corpóreas qualquer matéria a não ser aquilo que os geômetras denominam quantidade e tomam como objeto de suas demonstrações" (DESCARTES, 2000, p.67). Ou seja, em oposição à idéia de uma natureza viva, com lugares e corpos qualitativamente distintos (como o céu e a terra), Descartes procura mostrar que a realidade deve ser concebida como uma única natureza inanimada: a matéria ou substância extensa.

Tal mudança na compreensão da natureza da realidade veio acompanhada de uma mudança no modelo de conhecimento do mundo físico. O mundo físico (res extensa) aparece submetido às regras de comport amento impostas pela necessidade natural, ele nada mais é que o conjunto de leis e princípios que a própria ciência geométrica é capaz de extrair dos fenômenos. Nesse sentido, a física cartesiana opera com uma noção de matéria bruta, indiferente aos mecanismos da ação humana, a qual pode ser assimilada pela noção, freqüentemente mencionada nos escritos científico-filosóficos modernos, de qualidades primárias". A cera, examinada por Descartes, não é um produto natural envolto em práticas humanas, mas um "algo" amorfo, capaz de ser categorizado segundo os cânones da ciência, cujo interesse fundamental reside na apreensão de qualidades das coisas que não dependem em nada do observador. $\mathrm{O}$ investigador assume o papel de um observador distanciado, que contempla objetos dados no mundo indiferente da experiência ${ }^{4}$. 
No entanto, mesmo não assumindo um ponto de partida operativo, a idéia de apreender as leis matemáticas subjacentes que constituem a mecânica da realidade forneceu as bases para o desenvolvimento de uma concepção nova, aplicada e não contemplativa do conhecimento; a ciência passou a ser vista como uma "filosofia prática" capaz de nos garantir a posição de senhores da natureza.

Pois elas (algumas noções gerais relativas à Física) me fizeram ver que é possível chegar a conhecimentos que sejam muito úteis à vida, e que, em vez dessa Filosofia especulativa que se ensina nas escolas, se pode encontrar uma outra prática, pela qual, conhecendo a força e as ações do fogo, da água, do ar, dos astros, do céu e de todos os outros corpos que nos cercam, tão distintamente como conhecemos os diferentes misteres de nossos artífices, poderíamos empregá-los da mesma maneira em todos os usos para os quais são próprios, e assim nos tornar como que senhores e possuidores da natureza (DESCARTES, 1979b, p.63).

A redução da realidade à extensão (quantidade) e a apreensão de sua estrutura por uma razão que se exprime matematicamente já havia sido vislumbrada pela ciência pré-cartesiana. Descartes, no entanto, tratou de fornecer fundamentos metafisicos para a prática científica através da defesa da tese, aparentemente controve rsa para o leitor sensualista, da realidade como pura extensão, capaz de ser conhecida a partir da geometria.

Uma conseqüência epistemológica imediata desse contexto de mudanças na compreensão da natureza da realidade proveniente da fundamentação metafísica da ciência de Descartes foi fazer com que os sentidos perdessem o status de fontes centrais para o conhecimento empírico, tal como figurava na ciência antiga. Na tradição aristotélicotomista era uma tese comum que "todo conhecimento, incluindo o conhecimento de Deus, da alma, e das ve rdades matemáticas, é obtido por abstração intelectual a partir de particulares sensíveis"(HATFIELD, 1986, p.46). A mudança na concepção da realidade - imposta pela ciência moderna nascente que concebe a apreensão da estrutura da realidade em termos de propriedades quantificáveis representadas matematicamente - exigia uma nova epistemologia que tinha o espírito ou razão como fonte central do conhecimento ${ }^{5}$.

A apresentação de uma nova concepção acerca do modo pelo qual o 


\section{4}

conhecimento do mundo físico seria possível e o deslocamento dos sentidos a um papel de segundo plano para o conhecimento aparecem em várias partes da obra de Descartes ${ }^{6}$. Na Segunda Parte dos Princípios de Filosofia, que retomam as teses filosóficas das Meditações, chamada "Do conhecimento das coisas Materiais", Descartes diz:

Assim, pois, facilmente poremos de lado os prejuízos dos sentidos e nos utilizaremos aqui tão-somente do entendimento, que atenta diligentemente para as idéias colocadas nele pela natureza. Fazendo isso, perceberemos que a natureza da matéria, ou do corpo considerado em geral, não consiste no fato de ser uma coisa dura ou pesada ou colorida ou que afeta os sentidos de alguma outra maneira, mas tão-somente no fato de ser uma coisa extensa em comprimento, largura e profundidade (DESCARTES, 2002, p. 105).

Na Sexta Meditação, Descartes também afirma que as coisas corpóreas "talvez não sejam inteiramente como nós as percebemos pelos sentidos, pois essa percepção dos sentidos é muito obscura e confusa em muitas coisas..." (DESCARTES, 1979a, p. 135). Na Segunda Meditação, ele procura mostrar que a matéria (representada pelo pedaço de cera) concebida como extensão é clara e distintamente conhecida "pela tão só inspeção do espírito": "só concebemos os corpos pela faculdade de entender em nós existente e não pela imaginação nem pelos sentidos, e que não os conhecemos pelo fato de os ver ou de tocá-los, mas somente por os conceber pelo pensamento..." (DESCARTES, 1979a, p. 97-98).

É no interior desse contexto de reformulação do papel da ciência e dos mecanismos de apreensão da realidade física que se abriu o caminho para a aparição de hipóteses céticas metodológicas, hipóteses instrumentais que, quando devidamente meditadas, nos levariam à recusa da autoridade sensível e ao descobrimento de verdades evidentes, acessíveis à luz da razão, que fundamentariam de modo seguro todo nosso conhecimento. Além das verdades metafisicas que foram analisadas aqui havia outras que Descartes julgou relevante estabelecer. No entanto, a afirmação da tese, contra-intuitiva para a época, de que a realidade não é, em sua essência, um agregado de qualidades, mas matéria extensa a ser conhecida através das leis geométricas que presidem o movimento (pela razão e independentemente dos sentidos) oferece uma idéia suficientemente 


\section{clara do papel positivo que as dúvidas céticas desempenharam no proje- to cartesiano.}

1 Versões preliminares deste texto foram apresentadas no Colóquio UFRGS/UNISC de Filosofia ocorrido em maio de 2007 em Santa Cruz do Sul e no XII Encontro Nacional sobre Ceticismo Filosófico realizado na UFPR. Agradeço as sugestões e críticas que me foram endereçadas nestas oportunidades por Lia Levy, Luis Eva, Alexandre Machado, Paulo Faria, Rogério Passos Severo, Roberto Bolzani e César Schirmer dos Santos.

2 O Prof. Porchat é autor de um artigo notável onde indica uma série de razões para a conclusão de que o ceticismo acerca do mundo exterior teria sua origem entre os céticos gregos. Ele diz: "as doutrinas cartesianas da percepção representativa e do 'espaço interior' dos seres humanos' não constituem, de fato, uma novidade. A 'mente' não foi 'inventada' no século XVII, o estoicismo e o ceticismo grego conheceram-na a seu modo" [...] "dispomos de elementos mais que suficientes para asseverar que a pro blematização do mundo 'exterior' levada a cabo pelo ceticismo grego repousa [...] sobre uma teoria mentalista do conhecimento". O próprio Prof. Porchat se encarregou, noutro artigo, de indicar o anacronismo da aplicação dessas teses ao mundo grego. Cf. PORCHAT, O. Vida Comum e Ceticismo. 2.ed. São Paulo: Editora Brasiliense, 1994. p. 154-157.

${ }^{3}$ Harry Frankfurt apresenta esse ponto dizendo que Descartes pretendeu promover, através da dúvida, uma conversão intelectual: "a conversão da confiança nos sentidos para uma apreciação da função essencial da razão na aquisição do conhecimento". Cf. FRANKFURT, H. Demons, Dreamers and Madmen. 1970, p. 14. A suspensão das crenças fundadas nos sentidos produzida pela dúvida pretendia não tanto expor um argumento, mas funcionar essencialmente como um exercício, "uma espécie de exe rício mental...indispensável porque pro p o rciona os meios para livrar nossa atenção das idéias sensíveis a fim de apontar para uma fonte independente do conhecimento: as conquistas puras do intelecto". Cf. HATFIELD, G. 1986, p. 47.

${ }^{4}$ Num estudo acerca da imagem intelectual (Weltbild) da natureza do homem produzida pela filosofia em diferentes "Filosofias", Edward Craig procurou mostrar que é possível localizar uma tendência, partilhada por vários filósofos nos séculos XIX e XX, em direção àquilo que ele chamou de um "Ideal Prático", o qual se caracterizou pela transformação da concepção de homem moderna. Essa transformação consistiu em sustentar que, em lugar de ser concebido "como primeiramente e, antes de tudo, um espectador, um contemplador que pode e deve adquirir algum conhecimento da ordem da realidade como Deus a dispôs e assim realizar em algum grau seu potencial por afinidade com a mente divina", o homem passou a ser pensado como "um ser que ativamente cria, ou molda, seu próprio mundo" (CRAIG, 2000 , p.10, 224, 286). A concepção do ideal prático coloca o homem dentro do mundo conferindo-lhe um papel ativo. Nessa concepção, a verdade e o conhecimento não são pensados como algo separado da prática humana. Um exemplo dessa postura na filosofia contemporânea seria, segundo Craig, o pragmatismo de William James que sustenta que uma verdade absoluta não poderia ser alcançada pois "nossa única chance de conformar-nos a esta é que

doispontos, Curitiba, São Carlos, vol. 4, n. 2, p.103-118, outubro, 2007 
esta poderia coincidir com aquilo em que nós poderíamos ser conduzidos a acreditar de qualquer forma a partir de nossa experiência e a experiência de exercitar nossas faculdades." (CRAIG, 2000, p. 269). Assim, uma vez que estejam exauridos os interesses, criações e experiências que rodeiam a ação humana, não restaria nada para ser pensado. Em outros termos, o pragmatismo afirmaria que as únicas verdades que ele mesmo pode praticamente aceitar podem ser estas que suas experiências finitas o conduzem por si próprias. O Prof. Porchat também mostra, num recente artigo, que os germes de uma concepção ativa de nosso envolvimento com a natureza esteve presente na sofistica e no ceticismo grego.Ver PORCHAT, O. A autocrítica da razão no mundo antigo. In: FILHO, Waldomiro José Silva (Org.) O ceticismo e a possibilidade da Filosofia. Ijuí: Editora da Unijuí, 2005. p. 23-44.

5 GARBER, D. Descartes'Method and the Role of Experiment. In: COTTINGHAM, J. Descattes: Oxford Readings in Philosophy. Oxford: OUP, 1998, p. 234-258. Garber, fazendo referência a carta a Mersenne, diz: "Descartes deixa absolutamente claro que o programa das meditações não é um projeto filosófico autônomo, mas o prelúdio para um programa científico mais amplo; suas observações a Mersenne sugerem que a motivação das meditaçoos não podem ser meramente uma refutação do ceticismo, um problema que, como parece, não é de interesse fundamental para a prática do cientista". Cf. GARBER, D. "Semel in vita:The Scientific Background to Descarte's Meditations”. In: RORTY, A. (Org.) Essays on Descartes' Meditations. Berkeley: University of California Press, 1986, p. 83.

${ }^{6}$ Conforme explica Gary Hatfield, Descartes pretendia desenvolver "uma teoria precisa dos sentidos dando conta daquelas coisas cuja apreensão é em muitos aspectos obscura e confusa, a qual complementaria à compreensão da natureza das coisas corpó reas que seria objeto da matemática pura". Nesse sentido, Hatfield argumenta que a Física cartesiana admitiria a utilização de experimentos. Ver HATFIELD, 1986, p. 45.

\section{Referências bibliográficas}

BEYSSADE, M. 1996. Descartes. In: LABRUNE, M.; LAURENT, J. Gradus Philosophicus: a construção da filosofia occidental. Tradução de Cristina Murachco. São Paulo: Editora Mandarim.

COTTINGHAM, J. 1995. Dicionário Descartes. Rio de Janeiro. Jorge Zahar.

CRAIG, E. 2000. The Mind of God and the works of Man. Oxford: Oxford University Press.

DESCARTES, R. 1999. Oeuvres Philosophiques. Tome II (1638-1642). Edition de F. Alquié. Paris: Garnier. 1979a. Meditações Metafísicas. Tradução de Bento Prado 
e J. Guinsburg. São Paulo: Abril Cultural. (Coleção Os Pensadores). 1979b. Discurso do Método. Tradução de Bento Prado Júnior e J. Guinsburg. São Paulo: Abril Cultural. 1979c. Objeções e Respostas. Tradução de Bento Prado Júnior e J. Guinsburg. São Paulo: Abril Cultural. 2002. Princípios de Filosofia. Tradução de Guido Antônio de Almeida, Raul Landim Filho, Ethel Rocha, Marcos Gleizer, Ulisses Pinheiro. Rio de Janeiro: Editora UFRJ.

FRANKFURT, H. 1970. Demons, Dreamers and Madmen. The Defense of Reason in Descartes's Meditations. Indianapolis/New York: Bobbs-Merrill Company.

GARBER, D. 1986. "Semel in vita: The Scientific Background to Descarte's Meditations”. In: RORTY, A. (Org.) Essays on Descartes' Meditations. Berkeley: University of California Press. 1998. Descartes'Method and the Role of Experiment. In: COTTINGHAM, J. Descartes: Oxford Readings in Philosophy. Oxford: OUP, p. 234-258.

HADOT, P. 1996. Marco Aurélio: Meditações. In: LABRUNE, M.; LAURENT, J. Gradus Philosophicus: a construção da filosofia occidental. Tradução de Cristina Murachco. São Paulo: Editora Mandarim.

HATFIELD, G. 1986. The Senses and the Fleshless Eye: The Meditations as Cognitive Exercises.In: RORTY, A (Ed). Essays on Descartes' Meditations. Berkeley: University of California Press. . 1998. Force (God) ind Descartes's Physics. In: COTTINGHAM, D. Descartes. Oxford: Oxford University Press, p. 281-311.

PORCHAT, O. 1994. Vida Comum e Ceticismo. 2.ed. São Paulo: Editora Brasiliense. 2005. A autocrítica da razão no mundo antigo. In: FILHO, W. J. S. (Org.) O ceticismo e a possibilidade da Filosofia. Ijuí: 
Editora da Unijuí, p. 23-44.

STROUD, B. 1984. The Significance of Philosophical Scepticism. Oxford: Clarendon Press.

WILSON, M. 1978. Descartes. New York: Routledge. 